\title{
Cultural Studies vs. Political Economy: Is Anybody Else Bored with this Debate?
}

\section{LAWRENCE GROSSBERGI}

There is something disingenuous in the title of Nicholas Garnham's critique of cultural studies. The familial alternatives-reconciliation or divorce-imply that cultural studies and political economy were, at one time, "married" and, having recently separated, must now decide what to do." But cultural studies and political economy were never so intimate; after all, intimacy is itself a powerful social determinant. They were more like cousins who tolerated each other. And Garnham's essay reads like it is "addressed to the failings of a wayward child who is seen to be in need of stern parental (patriarchal) discipline."'3 Garnham is correct that cultural studies writers commonly and almost ritualistically distinguish themselves from their "reductionist" cousins. But he fails to acknowledge that every few years, some political economist-usually one involved with Media, Culture, and Society in Britain-writes the latest version of their attack on cultural studies, although the articles have not changed much since the mid-1970s. And they raise the same two criticisms: ${ }^{1}$ First, because cultural studies ignores the institutions of cultural production, it celebrates popular culture and gives up any oppositional role; second, because cultural studies ignores economics, it is incapable of understanding the real structures of power, domination, and oppression in the contemporary world.

I want not only to contest these criti-

Lawrence Grossberg holds the Morris Davis Chair of Communication Studies at the University of North Carolina. cisms, but also to challenge Garnham's history of the relation between cultural studies and political economy, for they have always been divided over the terms of an adequate theory of culture and power. The issue has always been how one thinks about the relationships or links between the different domains (forms and structures of practices) of social life. Cultural studies did not reject political economy per se-discussions of capitalism have always figured centrally in its work; rather it rejected the way certain political economists practice political economy. At the same time, I agree that there are particular positions in cultural studies that have become too celebratory of culture, in part because the commitment to the local and the specific have overshadowed any sense of the broader social context of unequal power relations. And I agree that there has been a tendency in some cultural studies to avoid detailed attention to the economic, in part because of the fear of falling back into reductionist models. But without a careful analysis of these devel opments and their place within the broader assumptive and political grounds of cultural studies, the value of such criticisms all but disappears.

Garnham's argument uses a number of conjoined discursive strategies that have become increasingly common weapons in political discourse (not only of the right against the left, but of fractions of the left against one another). First, to some extent, Garnham is criticizing culural studies for being cultural studies rather than political economy-for holding positions that it admits to holding--although Garnham's descriptions are 
usually just enough off the mark to make the positions sound silly. Thus, it is true that "cultural studies sees gender and race along with other potential markers of difference, as alternative structures of domination" to class, although I doubt that many people in cultural studies would argue that such differences are "in no way determined by those of class." In fact, what they are likely to argue is that any difference, and how it is livedwhether race, gender, class, sexuality, and so forth-is articulated to and by other differences. And the ways in which they are articulated make a difference in the formation of specific capitalisms (in particular countries, for example) rather than to some abstract capitalism. Garnham's political economy becomes ahistorical at just the points that matter: If capitalist societies (rather than modes of production) are variable, how does one understand those variations? Why is it that the USA is not the UK or Japan? These are not just superstructural problems, but issues about the ways social relations develop beyond a simple binary distinction between owners of the means of production and waged labor. But Garnham is unable to consider such questions precisely because he refuses to engage the question of articulation, which is, of course, the principal way in which the relations between production, consumption, politics, and ideology are theorized in cultural studies.

Second, his interpretation and indictment of cultural studies depends on what I would describe as sampling by convenience. The arguments of particular authors are selectively presented, and the range of work in cultural studies is alternatively narrowed (systematically ignoring others) or expanded beyond the scope of any recognizable notion of cultural studies. An example of the latter: Garnham's judgment of the "baleful" educational influence of cultural studies depends upon an expansion of the terrain to include those who simply equate cultural studies with the study of popular culture sans politics. An example of the former: While arguing that cultural studies ignores economics, Garnham seems to have conveniently forgotten that he has already mentioned the collective New Times project and my own analysis of the relationship between capitalism and culture in the New Right. But one could add others here-such as the important work of John Clarke, Meaghan Morris, Arjun Appadurai, Gayatri Spivak, Marcus Breen, and many others-as well as the wide-ranging discussions of globalization taking place. In fact, cultural studies is both narrower and broader than Garnham assumes, but that is, of course, because he never defines cultural studies nor identifies exactly whom he is criticizing. Instead it is simultaneously reified and selectively embodied.

Third, Garnham's interpretations of particular authors seem to operate by a reductio ad extremis - that is, by juxtaposing two authors writing about related topics, the more complex and moderate position can be equated to the more extreme and simplistic position. For example, I find it difficult to see how anyone can equate the following two bodies of work. On the one hand is work on consumption (and reception) in cultural studies, which looks at the complex and even contradictory nature of consumption and yes, often concludes that consumption can produce pleasures, that it can be, in some ways empowering, but which need not and does not deny the exploitative, manipulative, and dominating aspects of the market. Such work attempts to place local practices into the wider context of the social structures of power, even as it attempts to see how those structures are lived and felt locally. On the other hand is work which, for whatever reasons, argues that any act of consumption that is pleasurable, by definition is an act of resistance. Both bodies of work exist in cultural studies, but they are not the same. It is this misequation which appears to legitimate much of Garnham's critique, as well as that of McGuigan, whom Garnham cites. While I may agree that some work in cultural 
studies has been caught up in a rather celebratory mode of populism, I think it is absolutely necessary to distinguish this from the more prevalent and nuanced position of cultural studies. Moreover, Garnham ignores the fact that similar critiques of such extreme positions have been made by writers, especially feminists, within cultural studies itself (including Angela McRobbie, Meaghan Morris, John Clarke, Judith Williamson, and myself).

Finally, Garnham's indictment of cultural studies is often built on a critique by absence. This tendency is particularly common in the contemporary culture of the Left: Criticize a position for what it does not do or say. Obviously, it is one thing to claim that a position cannot talk about something, but it is quite another to claim that it has not talked about it. Thus, Garnham accuses cultural studies of paying too much attention to consumption, leisure, and everyday practices and not enough to production, work, and institutions: "Where in contemporary cultural studies are the studies of the cultural producers and the organizational sites and practices they inhabit and through which they exercise their power?" On the one hand, I am tempted to answer that they are in political economy; that is, after all, what political economists do, so why should they want cultural studies to do it? One could, after all, just as easily ask of political economy: Where are the studies of consumption and everyday life? But, on the other hand, it is important to answer: They are there in the works of people you have not cited, including Dorothy Hobson, Angela McRobbie (on the fashion industry), Sean Nixon, Jody Berland, and so forth. And they are also in the work of people studying organizational cultures. But perhaps the problem runs deeper, for what is assumed here is a rather narrow and abstract conception of production. If the very notion and practice of production are themselves culturally produced, and if the relations between production and consumption are more complex and less stable than Garnham suggests, then the model of cultural analysis based on d separation of production and consumption is itself problematic, as is the reduction of production to waged labor (which ignores what Marx himself had pointed out: the production involved in comsumption/reproduction). ${ }^{6}$

It is in fact rather telling that production here is so tightly equated with the "cultural industries" as if the commoditication of culture were somehow complete. Part of what cultural studies has always been about (especially in the very tradition of Williams/Hoggart/Ihompson of which (arnham is so fond) is the self-production of culture-the practices by which people come, however imperfectly, to represent themselves and their worlds. Important work (for example, by Mike Apple, Henry Giroux. Cameron McCarthy, Peter Mclaren, in education; by Bourdieu and his followers; by Foucauldeans looking at state discourse, and so forth) has also been done on cultural production in what used to be called the "ideological state apparatuses." Production cannot simply be the capitalized manufacture of cultural conmodities. Consider the ANC's decision to extend the cultural boycott to people as well as commodities, apparently recognizing that the embodied and personified practice of production is as imporlant as the commodities themselves.

Obviously, there is more than simply rhetoric at stake here. Perhaps cultural studies has paid too much attention io consumption, but I fear that what is operating behind such claims is the tendency to dismiss consumption (or leisure) as somehow less important than production, perhaps even as trivial. Production. narrowly understood as the practices of manufacturing, and abstractly understood as the mode of production is too easily assumed to be the real bottom line. Perhaps cultural studies has overemphasized the pleasure, freedom and empowerment of consumption (and reception), but again, I fear that what is 
operating behind such claims is the desire to return to a simpler model of domination in which people are seen as passively manipulated "cultural dupes." Certainly, some people in cultural studies have overemphasized the capacity for resistance in popular cultural practices, although I still see value in this work, not only as a provocation in the face of a still-puritanical Left, but also as a strategy for helping people see that things are not always the way authorities describe them, and moreover, that things do not have to be the way they are. Certainly, cultural studies often writes more about how systems of domination are lived than about the systems of domination themselves, and I agree that more work on the latter needs to be done. But without such work on how domination is lived, the Left is likely to fall back on old assumptions - and old generalizations at fairly high levels of abstraction-about the masses and everyday life.

On the other hand, it is simply not true to say that cultural studies does not look at dominant cultural practices; in fact, I am not sure what "dominant"--as opposed to popular-means in the contemporary capitalist context. Does Garnham mean elite or legitimate (via particular institutions of cultural capital)? Such differences are themselves institutionally constructed as both forms and expressions of power. Garnham claims that the capitalist structure of ownership prevents certain meanings from circulating: While I agree that not all meanings circulate equally along the same paths, I also think that there is little or nothing that is commercially unthinkable, although increasingly, it may be regulated by the state, moral agencies, and so forth. Of course, the fact is that different meanings may be differently sought out, taken up, and invested in. Once again, Garnham glosses over the real theoretical differences between the assumptions that, on the one hand, production is determining in the last instance, and on the other hand, production has its political and discursive conditions and vice versa.
Nor is it true to say that, in general, cultural studies adopts an uncritical populism. Most of the work in cultural studies that I read does not equate the popular with pleasure and resistance. It does not assume that all pleasure is good or politically progressive; on the contrary, it often recognizes that pleasure can be manipulated by or at least articulated to repressive forms of power and existing structures of inequality. And it recognizes that pleasures may themselves be repressive and regressive-for example those derived from relations of domination over other groups in formations of racism. Certainly this is a basic premise of most cultural studies work in feminism, postcolonialism, and critical race studies.

Cultural studies does not assume that opposition, resistance, struggle, and survival (coping) are the same; but it does assume that the possibilities for the first two depend in complex ways on the realities of the last two. The question of the relations and tensions among these forms of effectivity is important and needs to be explored. Perhaps most important is the question of what it is that mobilizes opposition. But I see no evidence that Garnham is either interested in addressing these questions, or capable of doing so. For cultural studies, the fact that people do use the limited resources they are given to find better ways of living, to find ways of increasing the control they have over aspects of their lives, is significant, not only in itself, but also in terms of understanding the structures of power and inequality in the contemporary world and the possibilities for challenging them. Cultural studies does assume that people live their subordination actively; that means, in one sense, that they are often complicit in their own subordination, that they accede to it, although power often works through strategies and apparatuses of which people are totally unaware. Be that as it may, cultural studies believes that if one is to challenge the existing structures of power, then one has to understand how 
that complicity, that participation in power, is constructed and lived, and that means not only looking at what people gain from such practices, but also at the possibilities for rearticulating such practices to escape, resist, or even oppose particular structures of power. Cultural studies refuses to assume that people are cultural dupes, that they are entirely and passively manipulated, either by the media or by capitalism. But it does not deny that they are sometimes duped, that they are sometimes manipulated, that they are lied to (and believe the lies, sometimes knowing that they are lies).

In both cases, Garnham's version of political economy, while apparently advancing a classical Marxist position, re fuses in practice to think about the contradictory nature of social practices. For Garnham, apparently, capital determines in a mechanical way from start to finish. Political economy thus has no way of thinking about contradiction (except in the most abstract, ahistorical from, such as the class contradiction) and therefore, it has no way of thinking about why things change. 'I'his, in my opinion, is not Marxist in the least!

Thus Garnham's position still leaves unanswered many important questions about how this domination, consent, and so forth, are accomplished and why they are successful (that is, how such attempts are able, sometimes, to help people $x$ cupy the positions they want). Perhaps some people in cultural studies exaggerate the possibilities or the freedom to interpret and use popular practices. But the choice is not, as Garnham would have it, between freedom and determination. Certainly economic practices and relations determine the distribution of practices and commodities (although not entirely by themselves), but do they determine which meanings circulate and which do not? I doubt it. Those articulations are much more complex and difficult to describe. The fact that certain institutions (and individuals) would like to control how people interpret. texts or what they do with them does nor mean that such "intentions" actually detemine what people do and think, that is. the effects of practices. Are the real effects determined? Of course, but in very complex ways, across a multiplicity of planes and dimensions, of codes and structures, as the result of particular struggles to articulate particular sorts of practices to particular sorts of effects. This relation between origins and effects is, as we shall see, a crucial issue between political economy and cultural studies.

Here we are beginning to get to the crux of the matter: Cultural studies believes that culture matters and that it cannot simply be treated (dismissed) as the transparent-at least to the critic.... public face of dominative and manipulative capitalists. Cultural studies emphasizes the complexity and contradictions. not only within culture, but in the relations between people, culture, and power. Now 1 am sure that Garnham would quickly respond that political economy also believes that culture ma! ters, but it is obvious from Garnham's paper that culture matters only as a $\mathrm{com}$ modity and an ideological wool of manipulation. And it is cleat as well that political economy has little room for complexity and contradiction-odd for a Marxist position. Here I want to consider two moments in Garnham's argument which, I think demonstrate the very real difference between political economy and cultural studies.

The first is what I would describe as Garnham's intentional misreading of the origins of British cultural studies. Cianham is certainly correct to describe the emergence of cultural studies as part of an oppositional, broadly socialist, political movement. But Garnham seems to equate "broadly socialist" with political economy. Cultural studies may have been (and 1 would hope still is) opposed to capitalism, its structures of inequality and exploitation, but that does not mean that it ever bought into political economy as a model of cultural explanation. On the contrary, there is plenty of evidence that its founding figures (especially Hoggar 
and Williams) quite intentionally distanced themselves from any attempt to explain culture in purely economic terms. Both cultural studies and the New Left, with which many of its leading figures were affiliated, distanced themselves from Marxism and its various models of culture, even while they operated within the space that it opened. And while it may be true that Thompson, Williams, and Hoggart all assumed that power in British society was organized entirely on the single dimension of class relations, this was not true of other important figures, such as Stuart Hall, nor of the New Left in general (which was, for example, concerned with issues of race and imperialism). And even the fact that they may have held such a view does not make it either correct nor constitutive of cultural studies. In fact, as early as 1968, the Centre for Contemporary Cultural Studies was exploring issues of the gendered relations of power, without assuming that these were merely epiphenomenal expressions of deeper, more real, bottom-line economic or class relations. Nor do I think that the founders of cultural studies as a group were as confident as Garnham suggests about who their friends and enemies were. ${ }^{8}$ In fact, Garnham fundamentally misunderstands the nature of cultural studies when he asserts that "cultural studies as a meaningful political enterprise ... is unsustainable outside the founding problematic." In fact, cultural studies as a meaningful political enterprise is sustainable only so long as its problematic is defined contextually, and thus is constantly open to challenge and change. Cultural studies is not a stable and closed enterprise; of course, unlike Garnham, I would also argue that political economy is also neither stable nor closed, that it is itself contested terrain.

Again, I am not denying the importance of a critique of capitalism to cultural studies, nor am I denying the prescriptive view that cultural studies should be "broadly socialist." I am denying, however, that such commitments should or even did entail particularly strong links to political economy, at least as I understand it or as Garnham defines it here. It is impossible that the two developments that Garnham identifies as central to contemporary cultural studies-more sophisticated theories of textuality and ideology and the widening of the concept of domination and subordination from class to include race and gender, and so forth-should "invalidate" the original links with political economy, since those links were not there in anything like the way Garnham needs for his argument. Moreover, even if they were, it would not matter; for the fact that cultural studies starts with a particular position cannot define its future-that is indeed one of its peculiarities and strengths.

This leads me to the second site that illustrates Garnham's dismissal of culture: namely, the extraordinarily offhand way he dismisses issues of identity and difference other than class, while ignoring that class itself is a culturally constructed identity. Here the concept of class conflates an abstract relation (defined at the level of the mode of production), a social relation, and an empirical referent. I do not quite know how to describe the glib way Garnham glosses decades of sustained intellectual and political work, as if it added up to nothing more than the recognition that black is beautiful-a recognition that, I might add, has in fact had important effects, despite Garnham's sarcasm. And then he glibly adds, "the same goes for gender." It is telling that Garnham's view of labor recomposition is that women entered waged work "increasingly at the expense of white male labor;" this is a telling indicator of what "class" is really about for Garnham-"at the expense of' indeed. ${ }^{9}$

Garnham's protests to the contrary, his position here strikes me as quite reductionist, as if class and economics (Garnham, by the way, conflates these) were all that really mattered. ${ }^{10} \mathrm{He}$ assumes a universal answer to the question of the nature of the determination be- 
tween economic and other social relations. This avoids what McRobbie (in press) describes as the "more awkward theoretical questions such as the nature of the political relationships which can and do exist between emergent social identities.... Much of the left prefers instead to rely on the assumed centrality of class as providing a kind of underpinning for the politics of race or sexuality." Thus, Garnham asks whether "cultural studies practitioners [would] deny that the major political/ideological struggles of the last decade in advanced capitalist countries have been around ... nar. rowly economic issues." In fact, of course, all sorts of issues having to do with race, gender, and sexuality come to mind-as well as issues of indigenous peoples, of disabled persons, of ecology and environmentalism-but that is beside the point. Garnham goes on to claim that such issues of "identity politics" are themselves rooted in "the restructuring of the labor market." and later he claims that modern forms of racial and gendered domination-in their genesis, forms, and stakes-are "founded" on economic domination. If race and gender are "economic" as well as social relations, I wonder what sort of economic relations they are? And how would Garnham account for them theoretically? That they are not detached from issues of capitalism is clear, but that they are "narrowly economic" is far from clear.

Obviously the changes, not only in the labor market but in the forms of labor. are one of the conditions of possibility (determinants) of the various contemporary "identity" issues. And the distribution of economic capital is absolutely cru. cial to the creation and maintenance of inequality. But does that mean that economics and class are in any sense adequate descriptions of all structures of power? The fact that modern forms of race and gender relations are themselves articulated in complicated ways by and to capitalist relations (including but not limited to class) does not mean that they are only or even primarily eco- nomic. No one in cultural studies denies the economic realities of racism or sex. ism, although they are likely to think that such inequalities cannot be directly mapped by or onto class relations. Moreover, they may also think that those inequalities are constructed in a variety of ways, along a variety of dimensions, be sides the distribution of labor and capital, and that some of those other wavs centrally involve cultural practices. The real issue is what it means to say that something is grounded or founded in something else: It need not be a description of origins, since as Garnham admit, racism and sexism preceded capilalism, but it also need not deline a suflicient condition of explanation. That is, the fact that race and gender are articulated to economics (and may be articulated to class) does not say much about the appropriate ways of accounting for, or struggling against, structures of domination organized around race and gender

Thus, while I do agree with Ganham (along with a number of key figures in cultural studies like Meaghan Morris) that 100 much work in cultural studics fails to take economics seriously enough, I am also convinced that political economy-at least this version of $\mathrm{jt}$ fails to take culture seriously enough. And ironically, I think it also fails to take capitalism seriously enough. Moreover. the way in which cultural studies takes economics seriously must be radically different from the assumptions and methods of political economy. For cultural studies does not believe that all forms of power can be explained by capitalist relations or in economic terms."

Despite Garnham's denials that political economy is either reductionist (whether economist or classist) or reflectionist (built on a base/superstructure model), I think his argument at least establishes that his version of political economy is too reductionist and reflectionist for cultural studies. (I apologize if this merely continues the "immense and damaging condescension of cultural studies," but then. I am not the one 
accusing someone of being complicitous with the Right.) No one in cultural studies denies that economic relations and practices "shape in determinate ways the terrain upon which cultural practices take place"--they may even in part help to shape the cultural agenda, but always and only in part. The question is, what follows from such statements? For the fact of the matter is, that for political economy, in every instance, in every context, somehow, almost magically, the economic appears to be the bottom line, the final and real solution to the problem, the thing that holds everything together and makes everything what it is. That is why, I believe, Hall argues that such reductionism and reflectionism are inIrinsic to Marxism (and by extension, to political economy). Everything seems to be locked into place, guaranteed by, economic relations. Garnham's own vocabulary betrays this: The fact is that "different modes of production will have a different set of ... superstructural relations." Consequently, and somewhat ironically, Garnham castigates Hall for using the Regulation School. The problem is that Hall reads them as antireductionists who refuse to assume a necessary correspondence between regimes of accumulation and modes of regulations (which do not exactly correspond to base and superstructure), while Garnham seems to think that as political economists, they must assume necessary correspondences, and hence, they must be reductionists in Hall's terms. The question is not whether Hall's reading is correct but whether it is possible to have a political economy theorized around articulation rather than strict determination or necessity.

And while Garnham denies the charge of functionalism-denies that superstructures are created "because the mode of production requires them"-he does assume a preexistant compatibility between the base and superstructure. Moreover, he speaks about the economy "entailing" particular modifications of cultural practices to particular ends. This sounds pretty close to functionalism to me. Finally, Garnham claims that rather than the superstructure merely reflecting the base, they are "linked" (presumably mediated) through the category of material interest; but presumably this is itself determined by and functional for the mode of production. For cultural studies, on the other hand, it is precisely because no specific fit or pregiven compatibility can be discerned between the base and the superstructure that the questions of cultural studies (and of cultural politics) become important. How can the variability of actually existing capitalism (and the practices within them) be explained? Thus, cultural studies argues that interests are themselves culturally produced, that part of what is involved in political struggles is the articulation of particular subject groups (particular identities) to particular interests. There are no originary and authentic interests, immediately and unproblematically defined by economic position, capable of linking the base (economics--or is it merely production for Garnham?) to the superstructure (or does consumption fall here under culture?). But this is preciselv what Garnham seems to assume and needs in order to then differentiate between such interests and the sort of needs and interests that are produced through cultural practices.

Thus the category of false consciousness returns-actually it has never left political economy. According to Garnham, without such a notion (and the related notion of truth), intellectuals have no valid role. And cultural studies of course rejects such notions. As I have said, cultural studies does not deny that, at times, people are duped, that they come to believe things that they ought not to believe. The question is whether this can serve as an adequate theory of ideology and/or culture, whether the vanguardist claims of Garnham's political economist--to know "the" truthcan be legitimated, or even whether they constitute a particularly effective political strategy. If people are so easily ma- 
nipulated, how can they be educated, or is the leftist critic merely to remanipulate people? A great deal has already been written in cultural studies on its refusal of notions of false consciousness. for Garnham to merely assert that such a notion is necessary for any politics is the height of condescension, to say nothing of ethnocentrism. My point here is not to defend the rejection of false consciousness, or merely to attack it once again (as elitist, and so forth). Rather my point is that Garnham's insistence on false consciousness merely reaffirms the readings of political economy he so vehemently claims to challenge.

But in the end, what is at stake is not so much the relations between cultural studies and political economy, but rather the ways in which questions of economics-and of contemporary capitalism in particular-are to be articulated into analyses of the politics of culture. For in a sense, cultural studies did not reject political economy, it simply rejected certain versions of political economy as inadequate. And such versions are characterized, not merely by their logic of necessary correspondences (reductionist and reflectionist), but by their reduction of economics to the technological and institutional contexts of capitalist manufacturing (with occasional gestures-and little more-to marketing. distribution and retailing), by their reduction of the market to the site of commodified and alienated exchange, ${ }^{12}$ and by their rather ahistorical and consequently oversimplified notions of capitalism. After all, to describe contemporary capitalism as dependent on waged labor and commodity exchange is, well, rather uninformative, as is the observation that contemporary culture is increasingly commodified. To point to the conditions of existence of capitalism as providing an adequate explanation of anything is to forget that Marx described them as "what every child knows." Such a political economy seems to assume that capitalism is a universal structure which, de spite minor variations (for example, in what is being commodified), remains un changed and stable. In fact, cultural studies did not reject political economy's in terest in capitalism. It rejected this political economy; it rejected both its description of the economy and its vision of the place of the economic in cultural and political analyses.

Contemporary cultural studies is, I believe, returning to questions of economics in important and interesting ways. Such work needs to be encouraged and developed even further. What cultural studies does not need is to return to some relationship that never actualiy $\mathrm{ex}-$ isted (and would not have been very good if it had). So I must dectine the invitation to reconcile, and point out that we don't need a divorce because we were never married. I would hope instead that we could learn to live together, if not in the same neighborhood. at least in the same region. We might nor like each other's taste or travel the same routes, but we can share a sense of the geography of power and the power of geography. We can criticize particular versions of each other's projects. More generally, we can criticize each other's assumptions; we can even criticize each other's political positions. But when we: start accusing each other of evacuating politics all together, of being traitors to the Left (that is, playing into the Right), then we have truly forgotten who the enemies are and where our allies (who may or may not be our friends) are to be found.

\section{NOTES}

'I am grateful to Stuart Hall, Angela McRobbie, and especially fohn Ciarke for their invaluable advice and suggestions.

2Of course, the details and implications of this metaphor-the particular set of gendered. heterosexual relationships-are left unexamincd. 
${ }^{3}$ John Clarke, personal correspondence.

${ }^{4}$ Interestingly, U.S. political economists, especially in the field of communication, for the most part, have been so dismissive of cultural studies that they ignore it entirely.

${ }^{5}$ See discussion of Sean Nixon's work in McRobbie (in press).

"Garnham's use of the "circuits" arguments (regarding the relation of production and consumption) is decidedly disappointing and unproductive. He would have been well advised to look at John Clarke's argument (1991) that consumption is not the same as exchange. "Consumption involves social practices after and beyond the exchange relation (including forms of production to realize specific use values). There is a significant issue about whether capitalists care about use values beyond their ability to realize exchange values" (John Clarke, personal correspondence).

${ }^{7}$ This paragraph is largely a paraphrase of arguments made to me by John Clarke in his comments on an earlier draft of this paper.

${ }^{8}$ In fact, my guess is that most people in cultural studies remember the 1960 s and 1970 s as a time when cultural studies had virtually no friends. Perhaps the problem today is that cultural studies has too many "friends" who are happy to tell us what it should be or what it is doing wrong.

${ }^{9}$ I am grateful to John Clarke for this observation.

${ }^{10}$ As Stuart Hall has pointed out (personal correspondence), this position is "preAlthusserian, pre-Gramscian." It seems to have ignored the various attempts within political economy of the 1970s and 1980s to save it from its own crude reductionisms.

"For example, in my own work (Grossberg, 1992) I have argued that while capitalism does not explain either the emergence or the efficacy of particular cultural formations, it is the case that the formations are currently being rearticulated to and by (that is, being deployed in the service of particular contradictions and struggles of contemporary capitalism.

${ }^{12}$ Angela McRobbie (in press) has described the marketplace as the "collision place of capitalist commerce with popular desires," and as "an expansive popular system."

\section{REFERENCES}

Clarke, J. (1991). Old times new enemies. New York: Routledge.

Grossberg, L. (1992). We gotta get out of this place: Popular conservatism and postmodern culture. New York: Routledge.

McRobbie, A. (in press). Looking back at New Times and its critics. In D. Morley \& K. H. Chen (Eds.), Stuart Hall and cultural studies. London: Routledge. 
Copyright of $C$ ritical Studies in Mass Communication is the property of National Communication Association and its content may not be copied or emailed to multiple sites or posted to a listserv without the copyright holder's express written permission. However, users may print, download, or email articles for individual use. 